\title{
ASPECTOS SOCIAIS E AMBIENTAIS DA CARCINICULTURA NO LITORAL SUL DO RIO GRANDE DO NORTE, BRASIL
}

\author{
SOCIAL AND ENVIRONMENTAL ASPECTS OF THE SHRIMP \\ FARMING IN SOUTH REGION OF THE RIO GRANDE DO \\ NORTE, BRAZIL
}

\author{
Aline Horácio da Costa \\ Mestre em Desenvolvimento e Meio Ambiente (PRODEMA - UFRN) \\ linehoracio7@gmail.com \\ Karina Ribeiro \\ Doutora em Aquicultura (UNESP-CAUNESP) e professora da UFRN \\ ribeiro_k@hotmail.com \\ Daniele Bezerra dos Santos \\ Doutora em Psicobiologia (UFRN) e professora da UNIFACEX-RN \\ danielebezerra@gmail.com \\ Cibele Soares Pontes \\ Doutora em Psicobiologia (UFRN) e professora da UFRN \\ cibelepontes2006@yahoo.com.br
}

\section{Resumo}

A busca da sustentabilidade na carcinicultura tem sido uma preocupação constante por parte dos produtores. Desta forma, a fim de avaliar a interação dos microprodutores de camarão do litoral Sul do Rio Grande do Norte junto aos padrões de responsabilidade ambiental recomendados pela Associação Brasileira de Criadores de Camarão (ABCC), aplicou-se questionários com o intuito de caracterizar as práticas de manejo adotadas, além de conferir os aspectos sociais e ambientais percebidos por eles produtores em função da atividade. Para tanto, foram entrevistados 27 produtores, sendo 85,2\% homens, com baixa taxa de analfabetismo (3,7\%), renda de 2 a 5 salários mínimos $(44,4 \%)$. Entre os entrevistados, $22,2 \%$ têm a carcinicultura como principal fonte de renda. Verificou-se que menos de $50 \%$ receberam assistência técnica no último ano e poucas são as medidas de biossegurança adotadas pelos mesmos. Com relação às boas práticas de manejo recomendadas pela $\mathrm{ABCC}, 11,1 \%$ dos carcinicultores fazem uso de probióticos e essa variável não possui relação com a renda mensal familiar ou ainda com as taxas de sobrevivência obtidas nos cultivos. Práticas de manejo, como fertilização da água e calagem do solo, assim como questionamentos sobre a problemática ambiental também não apresentaram relação com a escolaridade, havendo um manejo homogêneo entre os entrevistados. As micro propriedades produtoras de camarão, representativas da região do litoral Sul do Rio Grande do Norte, apontam a necessidade de orientação e apoio do governo e da devida assistência técnica para que possam implementar boas práticas de manejo, de forma a se adequar à carcinicultura responsável recomendada pela $\mathrm{ABCC}$.

Palavras-chave: Carcinicultores. Perfil socioeconômico. Práticas de manejo. Senador Georgino Avelino (RN). 


\begin{abstract}
The seeking for sustainability in shrimp farming has been a constant concern by producers. Thus, in order to evaluate the interaction of shrimp micro producers in the Southern coast of Rio Grande do Norte with the environmental responsibility standards recommended by the Brazilian Association of Shrimp Farmers (ABCC), questionnaires were applied in order to characterize the management practices, check over socials and environmental aspects perceived by the producers according to each activity. For this purpose, we interviewed 27 producers, from which $85.2 \%$ were men, with low illiteracy rate $(3.7 \%)$, income from 2 to 5 minimum wages (44.4\%). Among the interviewed, $22.2 \%$ have shrimp farming as their main source of income. It was found that less than $50 \%$ received technical assistance in the last year and few are the biosecurity measures adopted by them. With regard to good management practices recommended by the ABCC, $11.1 \%$ of shrimp farmers use probiotics and this variable has no link to the monthly family income or survival rates obtained in cultivation. Management practices, such as water fertilizing and soil liming, as well as questions about the environmental problems were not associated with schooling, with a homogeneous management among interviewed. The micro properties producers of shrimp representing the Southern coast of Rio Grande do Norte point the need of guidance and support of the government and appropriate technical assistance to enable them to implement good management practices, in order to suit the shrimp responsible recommended by the ABCC.
\end{abstract}

Keywords: Shrimp producer. Socioeconomic profile. Management practices. Senador Georgino Avelino (RN).

\title{
Introdução
}

A aquicultura é uma atividade econômica importante na produção de pescado (CAVALLI e FERREIRA, 2010) e um dos seus principais ramos é a criação de camarão. A carcinicultura marinha no Brasil teve seu início na década de 1970, mas começou a se destacar comercialmente apenas a partir da década de 90 com a introdução da espécie exótica de camarão marinho Litopenaeus vannamei. Alguns fatores foram essenciais para o estabelecimento da atividade, como o rápido crescimento dessa espécie, altas taxas de produtividade e rentabilidade, rusticidade e capacidade de desenvolver-se em uma ampla faixa de variação de salinidade. Além disso, a facilidade de nutrição e manejo nas mais diversas condições faz com que esta espécie seja a mais cultivada no Brasil e no mundo (FAO, 2008; SANTOS et al., 2009).

O crescimento da carcinicultura brasileira se deu de forma exponencial, destacando-se pela velocidade de ampliação da área ocupada pelas fazendas de engorda, como também do número de fazendas, da produção e das exportações. Durante muito 
tempo, a produção e o desempenho financeiro dessa atividade repercutiram em resultados positivos, por outro lado o rápido e indiscriminado crescimento acabou gerando problemas de ordem ambiental, econômica e social (RIBEIRO et al., 2014).

O estado do Rio Grande do Norte, que até 2009 liderou a produção nacional de camarão, atualmente ocupa a segunda posição, ficando atrás do Ceará. Apesar dos problemas enfrentados pela carcinicultura norte-rio-grandense, o estado ainda possui grande quantidade de produtores de camarão e esses estão distribuídos em polos camaroneiros, sendo o litoral Sul caracterizado pelo elevado número de microprodutores. São considerados empreendimentos de micro porte aqueles onde a carcinicultura é "realizada em viveiros ou tanques especiais, construídos em terreno natural, cuja somatória da área inundada produtiva, excluídos os canais de abastecimento, reservatórios e bacia de sedimentação, seja inferior ou igual a 5,0 (cinco) hectares" (RIO GRANDE DO NORTE, 2015).

Portanto, com o objetivo de promover, para empreendimentos que compõem a atividade, uma orientação abrangente e segura de como prevenir, controlar e, se possível, erradicar as enfermidades que afetam o camarão cultivado, a Associação Brasileira de Criadores de Camarão (ABCC) lançou, em 2012, o documento intitulado Procedimento de Boas Práticas de Manejo e Medidas de Biossegurança para a Carcinocultura Brasileira, que busca incentivar a regularidade na produção e a sustentabilidade da atividade (ABCC, 2012).

Dessa forma, entendemos que para a atividade de carcinicultura se desenvolver dentro dos padrões de responsabilidade recomendados pela $\mathrm{ABCC}$, é necessário considerar as orientações contidas nesse documento. Com base neste, elaboramos um questionário objetivando conhecer as práticas de manejo adotadas pelos microprodutores rde camarão do litoral sul do Rio Grande do Norte e, em paralelo, caracterizar os aspectos sociais e ambientais da carcinicultura percebidos por esses produtores.

\section{Metodologia}

\section{Área de estudo}

A área de estudo abrangeu o município de Senador Georgino Avelino

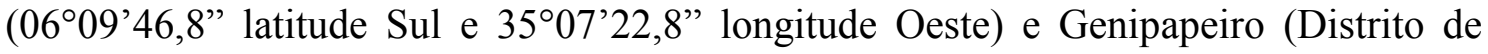


Nísia Floresta - 605’27,6” latitude sul e 35'12’32,4” longitude oeste). A localidade foi escolhida em função da grande quantidade de fazendas, consideradas de micro porte, de camarão já instaladas e em operação

\section{Aplicação das entrevistas e análises estatísticas}

O estudo foi realizado no mês de setembro de 2015 durante reuniões que estavam ocorrendo em função do cadastramento de microprodutores de camarão do litoral Sul pelo Instituto de Desenvolvimento Sustentável e Meio Ambiente do Rio Grande do Norte - IDEMA.

A pesquisa foi realizada por meio de um processo de amostragem aleatória simples, na qual os entrevistados foram selecionados aleatoriamente de uma listagem disponibilizada pelo IDEMA. O cálculo do tamanho da amostra resultou em 27 microprodutores de um total de 39 , o que representa $69 \%$ de toda a população em estudo. Após explicação pública sobre a pesquisa e seus objetivos, os participantes foram convidados a participar e, então, assinar o Termo de Consentimento Livre e Esclarecido (TCLE).

Em seguida, foram aplicadas entrevistas semiestruturadas, com a utilização de questionários contendo perguntas sobre características socioeconômicas dos produtores, infraestrutura da fazenda, práticas de manejo, medidas de biossegurança adotadas, medição de parâmetros físico-químicos da água e uso de novas tecnologias de produção, entre outras. No questionário, foram também abordadas questões específicas sobre a problemática ambiental envolvendo os impactos da carcinicultura e a geração de lixo durante os ciclos de cultivo.

Os dados serão apresentados através de estatística descritiva, por meio de frequências absolutas e relativas organizadas em tabelas e gráficos, e analisados pelo teste Exato de Fisher com relação à significância da associação observada entre variáveis categóricas numa tabela cruzada ou de contingência. Para as variáveis com múltiplas respostas, considerou-se cada categoria como sendo uma variável dicotômica (Sim/Não) e que para realizar os testes foi necessário agrupar categorias das variáveis escolaridade, renda mensal da família, uso de probióticos e percentual de sobrevivência 
nos cultivos. Todos os testes estatísticos foram realizados com um nível de significância 0,05 e o software utilizado foi o SPSS versão 20.

\section{Resultados}

Os produtores, em sua maior parte tinham entre 31-40 anos e 51-60 anos (Gráfico 1), do sexo masculino $(85,2 \%)$ e casados $(88,9 \%)$. Todos os entrevistados (100\%) residem em imóvel próprio, com famílias compostas de três a cinco pessoas (59,3\%). Observou-se que 66,7\% têm entre um e três filhos, existindo apenas três famílias $(11,1 \%)$ com mais de cinco pessoas. Possuem com escolaridade até o ensino fundamental $(40,7 \%)$ e médio completo $(44,4 \%)$ e apenas um dos entrevistados afirmou ser analfabeto (Gráfico 1).

Gráfico 1: Faixa etária e escolaridade dos microprodutores de camarão do litoral Sul do Rio Grande do Norte

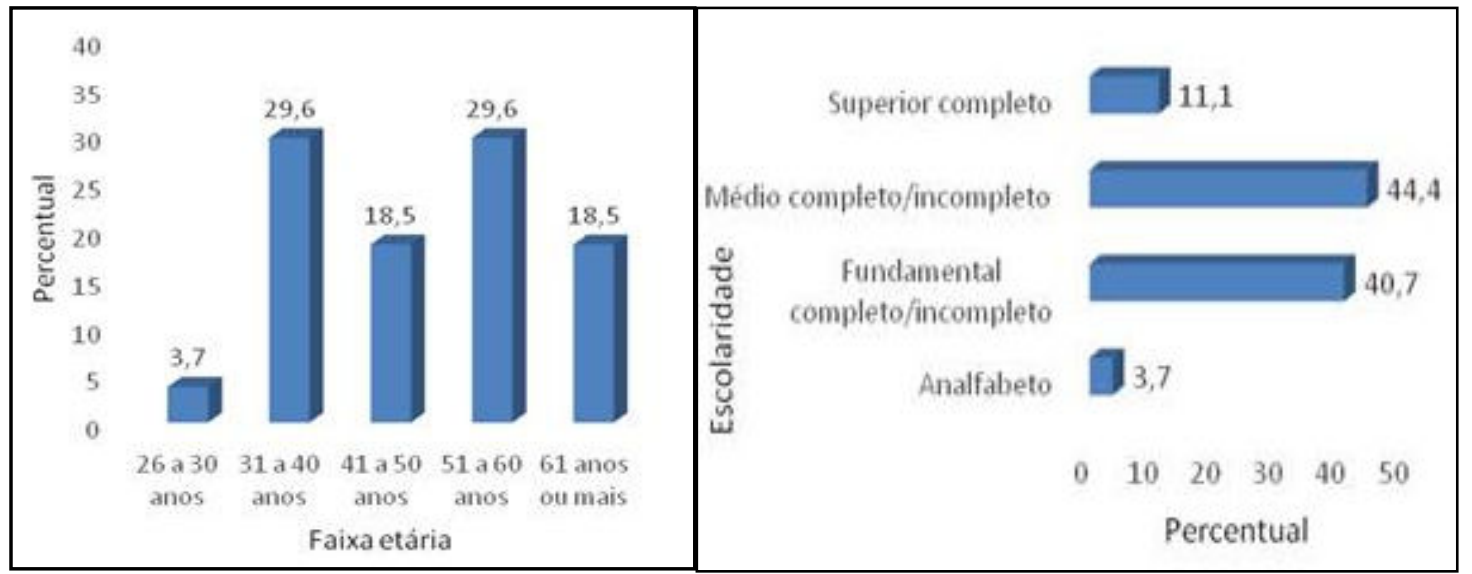

Fonte: Pesquisa de Campo, 2015.

Org.: Os autores, 2016.

Dentre os microprodutores, $70,4 \%$ informaram não receber benefícios do governo, enquanto $25,9 \%$ são aposentados e 3,7\% recebem benefícios do programa bolsa família. As principais fontes de renda listadas pelos produtores estão apresentadas no Gráfico 2, sendo a atividade de carcinicultura considerada a principal atividade econômica para $22,2 \%$ dos entrevistados. 
Gráfico 2: Principais fontes de renda listadas pelos microprodutores de camarão do litoral Sul do Rio Grande do Norte

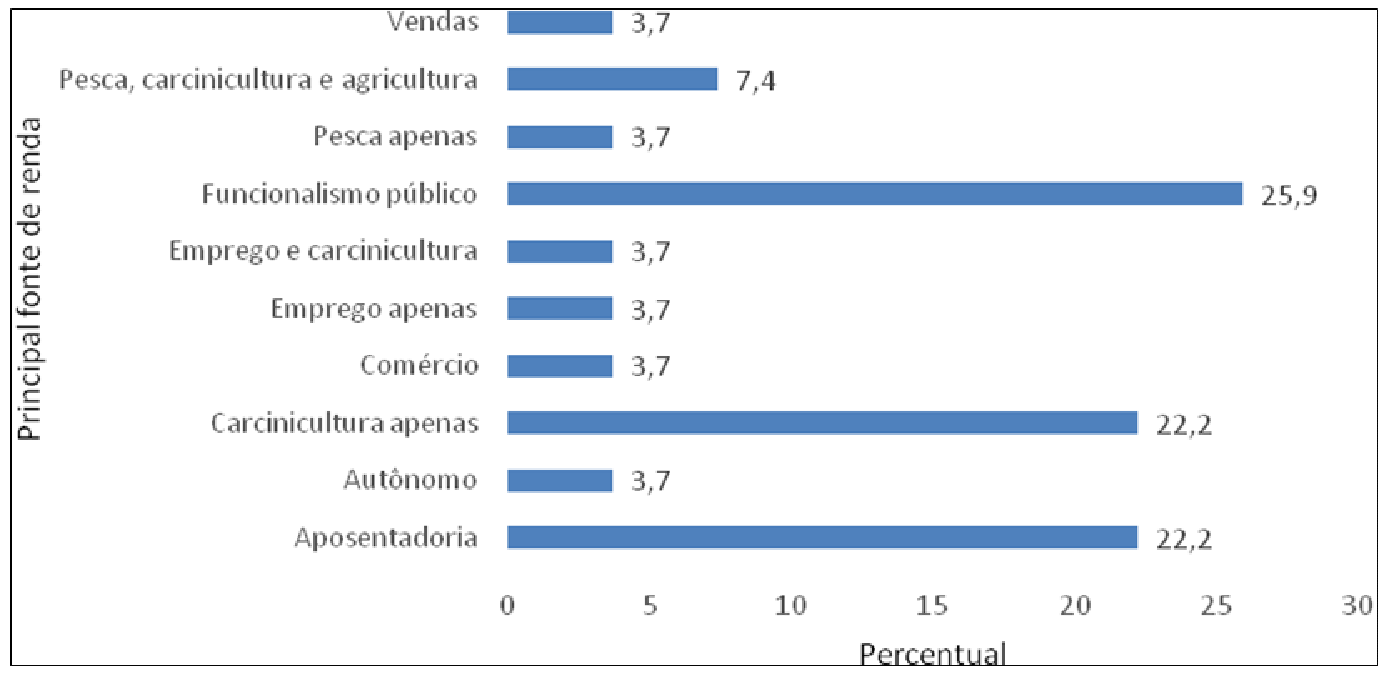

Fonte: Pesquisa de Campo, 2015.

Org.: Os autores, 2016.

A origem da terra que cultivam é, em sua maioria, de herança (59,6\%), seguida de compra $(25,9 \%)$, arrendamento $(7,4 \%)$, posse $(3,7 \%)$ e doação $(3,7 \%)$. Com relação à renda mensal familiar, a maior parte recebe de dois a cinco salários mínimos (Gráfico 3).

Gráfico: Renda mensal familiar (\%) dos micro-produtores de camarão do litoral Sul do Rio Grande do Norte em função do salário mínimo (SM) adotado no Brasil no ano de 2015

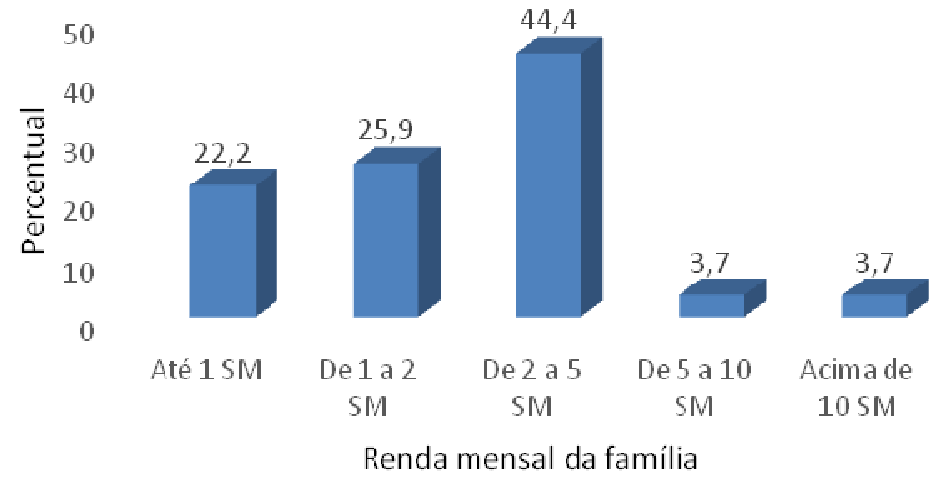

Fonte: Pesquisa de Campo, 2015.

Org.: Os autores, 2016.

Verificamos que $85,2 \%$ dos entrevistados que estão com os viveiros em plena atividade, enquanto $14,8 \%$ estão parados em função de altas mortalidades nos cultivos ou ainda por embargo pelo órgão ambiental competente. Um total de $48,1 \%$ relatou que 
a família também trabalha nos cultivos, $88,9 \%$ dos entrevistados não possuem empregados e os que têm $(11,1 \%)$ não assinam a carteira de trabalho.

Em relação à analise das técnicas de produção adotadas, os resultados obtidos encontram-se na Tabela 1.

Tabela 1: Manejo adotado em micro proriedades produtoras de camarão localizadas no litoral Sul do Rio Grande do Norte.

\begin{tabular}{|c|c|c|}
\hline Questões & Respostas & $\begin{array}{c}\text { Frequência } \\
\text { relativa }(\%) *\end{array}$ \\
\hline Como você cultiva os camarões? & Viveiro escavado & 100,0 \\
\hline \multirow{2}{*}{ Utiliza água de poço no cultivo? } & Sim & 11,1 \\
\hline & Não & 88,9 \\
\hline $\begin{array}{l}\text { Faz algum tipo de tratamento na água antes de } \\
\text { bombeá-las para os viveiros? }\end{array}$ & Não & 100,0 \\
\hline \multirow{2}{*}{ Faz fertilização da água? } & $\operatorname{Sim}$ & 18,5 \\
\hline & Não & 81,5 \\
\hline Usa disco de Secchi? & Não & 100,0 \\
\hline \multirow{2}{*}{ Faz calagem do solo? } & $\operatorname{Sim}$ & 77,8 \\
\hline & Não & 22,2 \\
\hline \multirow{2}{*}{ Adquire pós-larvas livres de enfermidades? } & $\operatorname{Sim}$ & 92,6 \\
\hline & Não & 7,4 \\
\hline Onde adquire as Pl's? & $\begin{array}{l}\text { Larvicultura } \\
\text { comercial }\end{array}$ & 100,0 \\
\hline \multirow{2}{*}{ Realiza aclimatação das pós-larvas? } & Sim & 70,4 \\
\hline & Não & 29,6 \\
\hline \multirow[t]{2}{*}{ Qual a duração da fase berçário? } & Não tem berçário & 100,0 \\
\hline & Compra sozinho & 88,9 \\
\hline \multirow[t]{2}{*}{ Como é o planejamento para a compra de ração? } & $\begin{array}{l}\text { Compra associado a } \\
\text { outro produtor }\end{array}$ & 3,7 \\
\hline & Outro & 7,4 \\
\hline
\end{tabular}


Você escolhe a ração em função:

Da facilidade de encontrar no mercado

$\operatorname{Sim}$

11,1

Do preço.

Da qualidade (percentual de proteína)

Não

88,9

$\operatorname{Sim}$

74,0

Não

26,0

$\operatorname{Sim}$

51,9

Não

48,1

Qual a frequência da oferta de alimento/dia?

Duas vezes

92,6

Outro

Quantas vezes faz o ajuste de ração em um ciclo de

Diariamente

96,3

cultivo

Três vezes

Como fornece a ração?

Bandeja

100,0

A sobra de ração é retirada?

$\operatorname{Sim}$

92,6

Não

Uma vez por semana

Com qual frequência realiza biometrias durante o cultivo?

Outros

Não realiza biometria

Faz medição de quais parâmetros físico-químicos da água?

Temperatura

$\operatorname{Sim}$ 11,1

Não

88,9

Salinidade

Sim

37,0

Não

63,0

$\mathrm{pH}$

Sim

Não

96,3

Oxigênio dissolvido

Sim

11,1 


\begin{tabular}{lcc}
\hline & Não & 88,9 \\
Alcalinidade & Sim & 11,1 \\
& Não & 88,9 \\
Dureza & Sim & 3,7 \\
& Não & 96,3 \\
Turbidez & Sim & 3,7 \\
& Não & 96,3 \\
Amônia tóxica & Sim & 3,7 \\
& Não & 96,3 \\
Nitrito & Sim & 3,7 \\
& Não & 96,3
\end{tabular}

O que faz para controlar a matéria orgânica no fundo dos viveiros?

Retira

Usa probióticos

Não

Não

100,0

Deixa secar ao sol

Sim $\quad 88,9$

Não

Não controla

Sim $\quad 3,7$

Não

Faz uso de probióticos com qual finalidade?

Melhoria na qualidade de água

$\operatorname{Sim}$

\begin{tabular}{|c|c|}
\hline \multirow{3}{*}{ Maior crescimento } & Não \\
\hline & Sim \\
\hline & Não \\
\hline \multirow[b]{2}{*}{ Não faz uso } & Sim \\
\hline & Não \\
\hline
\end{tabular}

Para os entrevistados que não fazem uso de probióticos (Tabela 1), os motivos são apresentados no Gráfico 4. 
Gráfico 4: Motivos pelos quais os microprodutores de camarão do litoral Sul do Rio Grande do Norte não fazem uso de probióticos nos cultivos

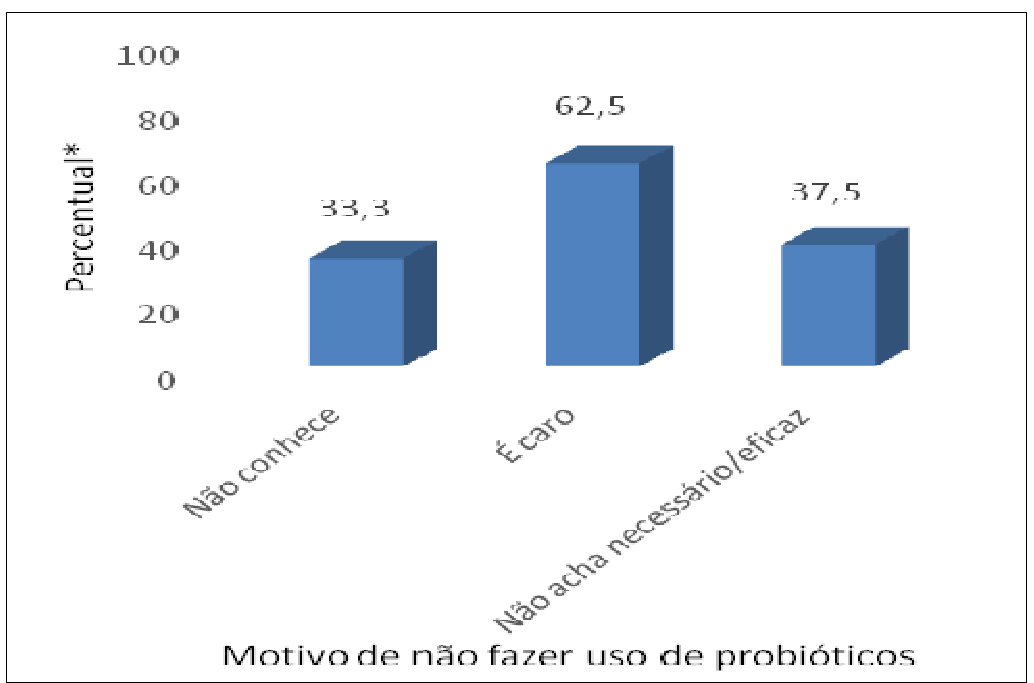

(*) percentual em relação ao total de entrevistados que não faz uso de probióticos. Múltiplas respostas. Fonte: Pesquisa de Campo, 2015.

Org.: Os autores, 2016.

Os cultivos, que no momento de crescimento da atividade na região, ultrapassavam 90 dias, hoje têm seus dias abreviados (Gráfico 5) em função do recorrente aparecimento de doenças, e muitas vezes contam com baixas sobrevivências (Gráfico 6).

Gráfico 5: Tempo total médio de um ciclo de cultivo realizado em micro propriedades produtoras de camarão localizadas no litoral Sul do Rio Grande do Norte

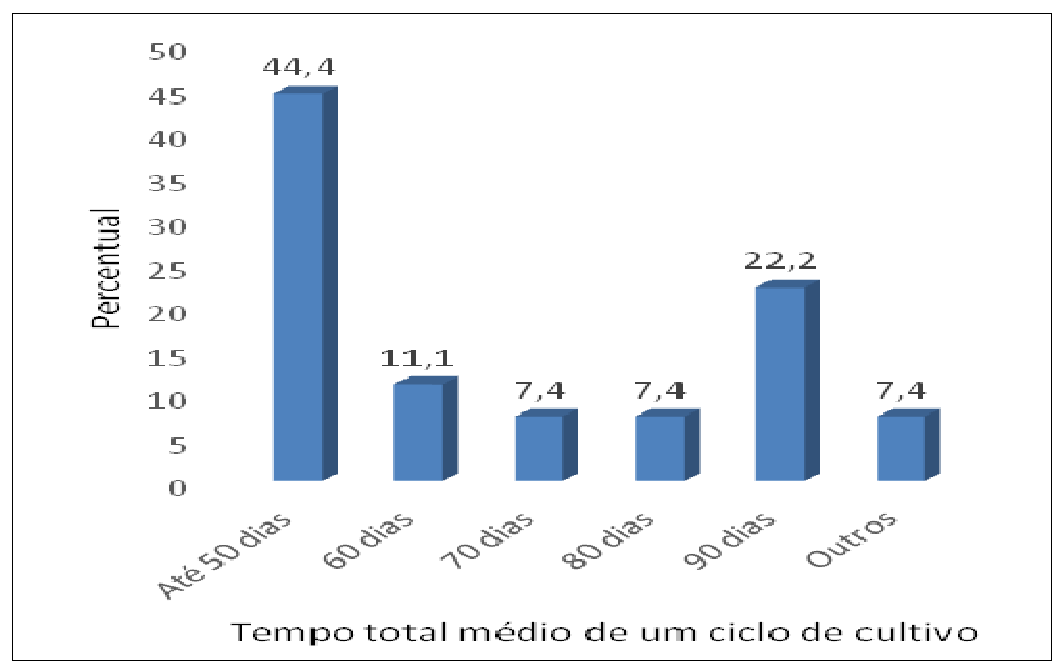

Fonte: Pesquisa de Campo, 2015.

Org.: Os autores, 2016. 
Gráfico 6: Sobrevivência dos cultivos realizados em micro propriedades produtoras de camarão do litoral Sul do Rio Grande do Norte

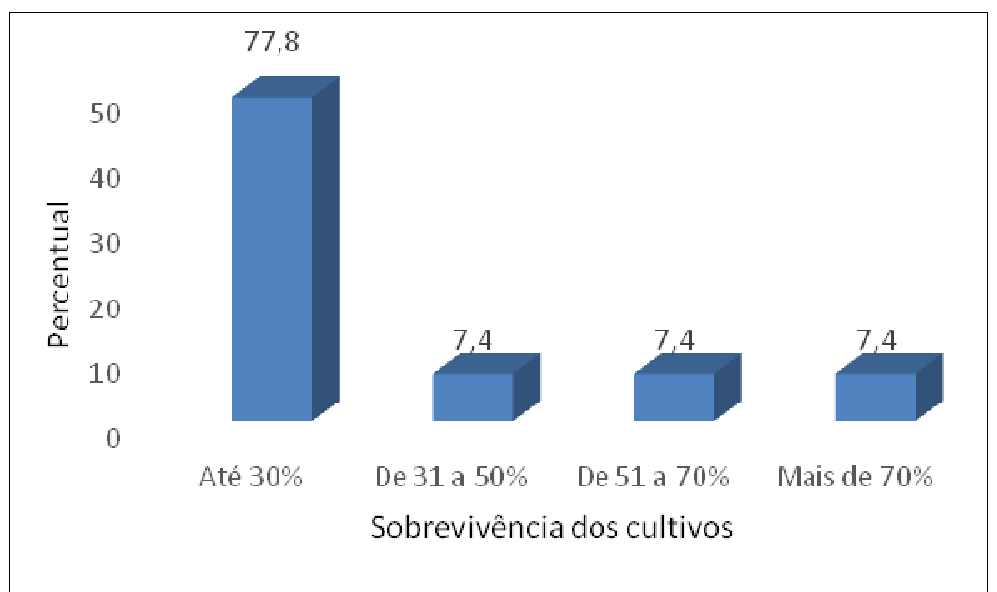

Fonte: Pesquisa de Campo, 2015.

Org.: Os autores, 2016.

Para 96,3\% dos entrevistados, o percentual de sobrevivência diminuiu consideravelmente nos últimos cinco anos e 3,7\% afirmaram estar ainda em seu terceiro ciclo de cultivo. O tempo de cultivo (Gráfico 5), nesse caso, está relacionado com a sobrevivência, uma vez que quando os camarões começam a morrer, a retirada dos animais dos viveiros é feita emergencialmente.

Quando questionados, sobre a que se pode atribuir essa variação da sobrevivência, $81,5 \%$ consideraram a incidência de doenças, $11,1 \%$ a água contaminada e $7,4 \%$ ao solo envelhecido, enquanto $11,1 \%$ não souberam responder.

Sobre a despesca, quase todos os entrevistados $(92,6 \%)$ a realiza de forma total, enquanto 7,4\% parcial. A despesca parcial foi justificada em ser realizada em virtude do pagamento de despesas do próprio cultivo. Ainda em relação à produção, na maioria dos casos $(88,9 \%)$, é comprada por atravessadores, que a escoam para o comércio, sendo relativamente baixa a venda direta aos consumidores (11,1\%). Todo o camarão produzido é comercializado inteiro (100\%).

No que diz respeito à questão ambiental, 81,5\% dos produtores afirmaram possuir licença ambiental, embora os microempreendedores estejam passando por um processo de ajuste legal em função da Lei Cortez Pereira. Questionou-se ainda a visão dos produtores quanto aos impactos negativos da carcinicultura junto ao meio ambiente, sendo que a maioria (88,9\%) não vê a atividade como impactante. Entretanto, 3,7\% dos entrevistados acreditam que destrói áreas de manguezal, 3,7\% acham que piora a 
qualidade da água no entorno da fazenda e 3,7\% não souberam responder.

Ao serem questionados quanto ao uso de bacias de sedimentação, 96,3\% dos entrevistados afirmaram que sua fazenda não possui e, portanto, os efluentes são despejados diretamente no manguezal. Muitos dos entrevistados afirmam que não geraram impactos ambientais uma vez que não usam produtos químicos, enquanto que os outros produtores (médios e grandes) os utilizam. Um total de 93,6\% dos entrevistados acham que o cultivo não gera muito lixo (resíduos sólidos) e $88,9 \%$ não consideram necessário haver um programa de reciclagem, pois todo o lixo produzido já é reutilizado por eles, como os sacos de ração e de pós-larvas.

Sobre a assistência recebida no último ano, 33,3\% afirmaram terem sido assistidos pelo Serviço Brasileiro de apoio às Micro e Pequenas Empresas - SEBRAE, enquanto 3,7\% pela $\mathrm{ABCC}$ e 7,4\% pela Cooperativa dos Produtores de Camarão Marinho do Estado do Rio Grande do Norte - Coopercam. No entanto, nenhum dos produtores citou o extinto Ministério da Pesca e Aquicultura ou qualquer outra assistência.

No que diz respeito às medidas de biossegurança, nenhuma fazenda possui controle e acesso de veículos e visitantes, rodolúvio, pedilúvio e os controles de pragas, animais silvestres e domésticos. Entretanto, 100\% dos entrevistados monitoram a saúde dos animais diariamente com análises visuais, mas não fazem qualquer tipo de análise laboratorial, pois $96,3 \%$ afirmaram não ter acesso aos meios e 59,3\% consideram caro.

Um total de $100 \%$ dos produtores afirmou já ter vivenciado enfermidades em suas fazendas (Gráfico 7) e que não fizeram nenhuma análise para determinar o tipo de doença e 88,9\% afirmaram que não usaram antibióticos.

Devido ao surgimento dessas doenças, $85,2 \%$ dos entrevistados já tiveram que desativar o(s) viveiro(s) por algum tempo, acarretando em prejuízos. Em todos os surtos ocorridos, $100 \%$ dos produtores realizaram uma despesca emergencial, sendo a água do cultivo lançada sem tratamento no meio ambiente. Um total de 59,3\% comunicou às fazendas vizinhas que estavam com animais doentes. Aqueles que não comunicaram (40,7\%) disseram que não havia necessidade, pois todos já ficam sabendo, principalmente, quando as garças começam a sobrevoar os viveiros. 
Gráfico 7: Doenças que apareceram nas fazendas de microprodutores de camarão do litoral Sul do Rio Grande do Norte. (*) múltiplas respostas

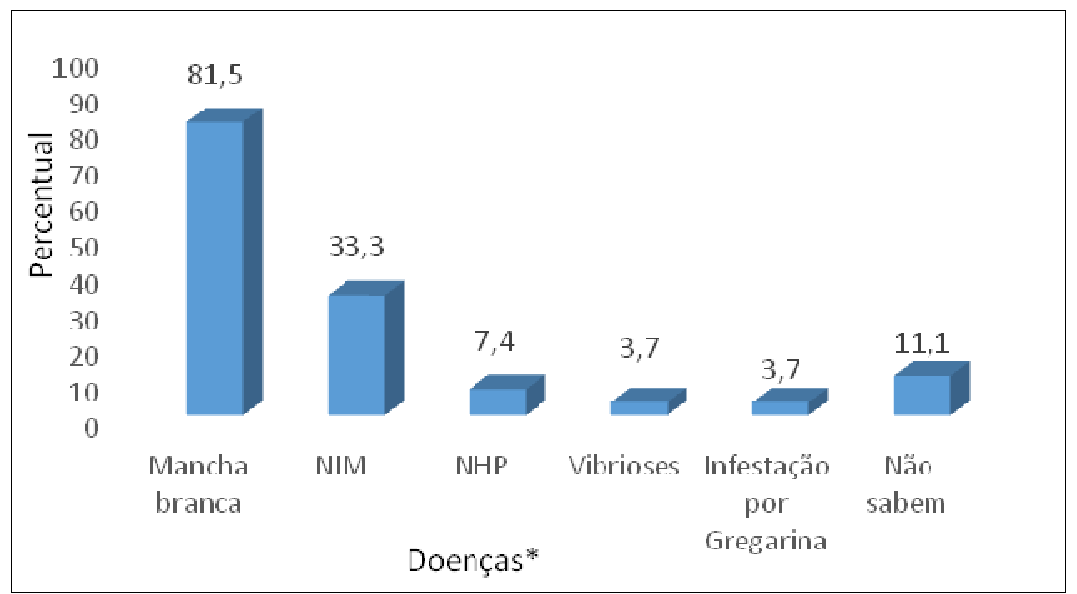

Fonte: Pesquisa de Campo, 2015.

Org.: Os autores, 2016.

Para melhorias na atividade de carcinicultura, os entrevistados listaram alguns itens (Gráfico 8). Com relação ao acesso a crédito bancário para a aquicultura, apenas $25,9 \%$ o obtiveram. No entanto, todos os produtores afirmaram que sua fazenda beneficia a comunidade do entorno pela geração de emprego temporário e renda para a população, principalmente, nas épocas de despesca e preparação dos viveiros para os cultivos. Um produtor (3,7\%) ainda citou a venda de camarão barato para os moradores da região.

Gráfico 8: Itens listados pelos microprodutores de camarão do litoral Sul do Rio Grande do Norte como necessários para melhorar a atividade de carcinicultura na região



(*) múltiplas respostas.

Fonte: Pesquisa de Campo, 2015.

Org.: Os autores, 2016. 
De acordo com correlações realizadas (Tabela 2), e com o teste Exato de Fisher, não há indícios de associação linear $(p>0,05)$ entre o nível de escolaridade e todas as variáveis ligadas ao manejo empregado pelos produtores, ou seja, o manejo independe do grau de escolaridade do micro produtor. Para as variáveis sobre a questão ambiental, os resultados foram semelhantes: independem da escolaridade. Ao realizar o mesmo teste para as variáveis renda mensal da família e porcentagem de sobrevivência contra o uso de probióticos, verificou-se que também não há evidências de associação.

Tabela 2: Frequências relativas (\%) e valor-p do teste Exato de Fisher de associação entre a variável escolaridade e variáveis relacionadas ao manejo empregado e questão ambiental; entre a variável uso de probióticos e renda mensal da família e percentual de sobrevivência nos cultivos

\begin{tabular}{|c|c|c|c|c|}
\hline & & Escolaridade & Valor-p* & \\
\hline Manejo empregado & Resp. & Até $1^{0}$ grau & $2^{0}$ grau ou mais & \\
\hline \multirow[t]{2}{*}{ Utiliza água de poço no cultivo? } & Sim & $8,3 \%$ & $13,3 \%$ & 0,5863 \\
\hline & Não & $91,7 \%$ & $86,7 \%$ & \\
\hline \multirow[t]{2}{*}{ Faz fertilização da água? } & Sim & $16,7 \%$ & $20,0 \%$ & 0,6121 \\
\hline & Não & $83,3 \%$ & $80,0 \%$ & \\
\hline \multirow[t]{2}{*}{ Faz calagem do solo? } & Sim & $66,7 \%$ & $86,7 \%$ & 0,2188 \\
\hline & Não & $33,3 \%$ & $13,3 \%$ & \\
\hline \multirow[t]{2}{*}{ O que faz para controlar a matéria } & Sim & $83,3 \%$ & $100,0 \%$ & 0,1880 \\
\hline & Não & $16,7 \%$ & $0,0 \%$ & \\
\hline \multirow[t]{2}{*}{ Deixa secar ao sol } & Sim & $91,7 \%$ & $86,7 \%$ & 0,5863 \\
\hline & Não & $8,3 \%$ & $13,3 \%$ & \\
\hline \multirow[t]{2}{*}{ Não controla } & Sim & $8,3 \%$ & $0,0 \%$ & 0,4444 \\
\hline & Não & $91,7 \%$ & $100,0 \%$ & \\
\hline \multicolumn{5}{|l|}{ Questão ambiental } \\
\hline \multirow[t]{2}{*}{ Destruição do ecossistema } & Sim & $0,0 \%$ & $6,7 \%$ & 0,5556 \\
\hline & Não & $100,0 \%$ & $93,3 \%$ & \\
\hline \multirow[t]{2}{*}{ Piora da qualidade da água no } & Sim & $0,0 \%$ & $6,7 \%$ & 0,5556 \\
\hline & Não & $100,0 \%$ & $93,3 \%$ & \\
\hline Não gera impactos & Sim & $100,0 \%$ & $80,0 \%$ & 0,1556 \\
\hline
\end{tabular}




\begin{tabular}{|c|c|c|c|c|}
\hline & Não & $0,0 \%$ & $20,0 \%$ & \\
\hline \multirow[t]{2}{*}{ Você acha que o cultivo gera } & Sim & $0,0 \%$ & $6,7 \%$ & 0,5556 \\
\hline & Não & $100,0 \%$ & $93,3 \%$ & \\
\hline \multirow{4}{*}{$\begin{array}{l}\text { Você acha necessário que } \\
\text { houvesse um programa de }\end{array}$} & Sim & $8,3 \%$ & $13,3 \%$ & 0,5863 \\
\hline & Não & $91,7 \%$ & $86,7 \%$ & \\
\hline & & $\begin{array}{c}\text { Uso de } \\
\text { probióticos }\end{array}$ & Valor-p* & \\
\hline & & Sim & Não & \\
\hline \multirow[t]{2}{*}{ Renda mensal da família } & Até 2 & $0,0 \%$ & $54,2 \%$ & 0,1244 \\
\hline & Acima & $100,0 \%$ & $45,8 \%$ & \\
\hline \multirow[t]{2}{*}{ Qual é a porcentagem de } & Até & $33,3 \%$ & $83,3 \%$ & 0,1145 \\
\hline & Acima & $66,7 \%$ & $16,7 \%$ & \\
\hline
\end{tabular}

Resp. $=$ Resposta

(*) Teste Exato de Fisher

$\mathrm{SM}=$ salário mínimo

Fonte: Pesquisa de Campo, 2015.

Org.: Os autores, 2016.

\section{Discussão}

A carcinicultura é uma das atividades comerciais que mais crescem no Nordeste brasileiro, sendo de grande representatividade no cenário nacional (CAVALCANTI, 2012). Scorvo Filho et al. (2010) afirmaram que a carcinicultura tem se moldado a novos padrões, com uso de menor densidade de estocagem nos viveiros e manejos sanitários e profiláticos. Recentemente, a atividade de carcinicultura do Rio Grande do Norte (RN) passou a ser regulamentada, além de outros instrumentos legais, pela legislação estadual No 9978 de 09/09/2015 (denominada Lei Cortez Pereira), fazendo com que os microprodutores estejam sujeitos a um processo de adequação legal no órgão ambiental competente (IDEMA-RN). De acordo com a lei em questão, a atividade de carcinicultura como um todo passou a ser considerada no RN uma atividade agrosilvipastoril, denominadas como "atividades desenvolvidas em conjunto ou isoladamente relativas à agricultura, à aquicultura, à pecuária, à silvicultura e demais formas de exploração e manejo da fauna e da flora, destinadas ao uso econômico, à 
preservação, e à conservação dos recursos naturais renováveis".

A Lei Cortez Pereira estabelece também outros conceitos importantes para entendermos a situação da carcinicultura no estado, caracterizando os empreendimentos de micro porte como referentes à carcinicultura realizada em viveiros ou tanques especiais, construídos em terreno natural, cuja somatória da área inundada produtiva, excluídos os canais de abastecimento, reservatórios e bacia de sedimentação, seja inferior ou igual a 5,0 (cinco) hectares.

A bacia de sedimentação é definida como unidade de decantação das águas de drenagens por ocasião das despescas da carcinicultura, correspondente a $10 \%$ do volume total da área inundada produtiva, excluídos os canais de abastecimento, reservatórios e bacia de sedimentação, com a finalidade de deposição dos sólidos em suspensão, permitindo tanto o reaproveitamento, via recirculação d'água ou o deságue no corpo receptor, sem riscos de degradação ambiental.

Apesar de incluir a bacia de sedimentação nos conceitos aplicados aos empreendimentos de micro porte, a Lei Cortez Pereira especifica ainda que no caso de cultivo em viveiros escavados ou tanques especiais é permitida a utilização de espécies autóctones, alóctones e exótica, incluindo a reintrodução ou transferência, desde que obedecidos alguns requisitos. Dentre estes requisitos, estabelece que a derivação das águas de drenagem para bacias de sedimentação, ou diretamente para rios ou estuários se apresentarem qualidade igual ou superior recebidas no ato de captação. Desta forma, o micro produtor fica desobrigando à utilização de bacia de sedimentação, o que é preocupante uma vez que, de acordo com nossa pesquisa, a quase totalidade dos entrevistados não monitoram a qualidade da água de seus cultivos e 96,3\% dos entrevistados afirmaram que sua fazenda não possui bacia de sedimentação e portanto, os efluentes são despejados diretamente no manguezal. Podemos inferir a necessidade dos microprodutores em realizar as análises de água ficando assim resguardados para eventuais fiscalizações.

Observamos que, no caso das micro propriedades de produção de camarão do litoral Sul, a diminuição da densidade de estocagem surgiu como um reflexo do surgimento das doenças, o que resulta sempre em quedas na produtividade e no lucro. Para a maioria dos produtores entrevistados, a carcinicultura já foi a sua principal fonte 
de renda e não o é mais. Já sobre a mudança para manejos sanitários e profiláticos citados por Scorvo Filho et al. (2010), foi verificado que ainda não ocorreu na região estudada devido a condição financeira dos produtores, sendo que a única medida de manejo de água e solo citada a calagem do solo. Esta pratica é comumente empregada para a correção do $\mathrm{pH}$ em aquicultura e consiste na adição de calcário agrícola, tanto na água quanto no solo dos viveiros (VINATEA et al., 1997).

Alguns dos resultados da expansão acelerada da carcinicultura no Brasil foram a geração de emprego e a absorção da população local com nível básico de escolaridade (COSTA e SAMPAIO, 2004). Os empregos diretos gerados pela carcinicultura demandam, em sua maioria, pouco grau de instrução formal, pois as atividades desenvolvidas são basicamente de arraçoamento, monitoramento da qualidade da água e biometria do camarão (FIGUEIRÊDO et al., 2004). No entanto, observamos que para o litoral Sul do RN uma minoria de donos de micro empreendimentos possui baixo nível de escolaridade, sendo $3,7 \%$ analfabeto e $37 \%$ concluintes do ensino médio.

A comercialização de camarão no Brasil se dá principalmente no mercado interno (SCORVO FILHO et al., 2010). Os dados apresentados demonstram que a maioria dos entrevistados escoa toda a produção para os atravessadores, corroborando com Lopes e Baldi (2013), que ao entrevistarem representantes do setor de aquicultura, observaram que os agentes intermediários são importantes componentes dessa estratégia de exploração do mercado nacional. Os produtores de camarão marinho de Requenguela/CE também não se preocupam com a comercialização do produto, pois existe um parceiro que garante a compra da produção (REIS, 2008).

A comunidade de Requenguela, localizada no município de Icapuí - Ceará, é composta por aproximadamente 35 famílias e a principal fonte de renda está na pesca da lagosta e na aquicultura (REIS, 2008). Em comparação, no nosso estudo pelos menos $37 \%$ dos entrevistados citaram carcinicultura ou pesca como principal fonte de renda. Em contraste, de acordo com Reis (2008) a Associação dos Produtores de Camarão Marinho de Requenguela é formada por associados de 20 famílias, os quais possuem baixa escolaridade, tendo esse fato dificultado a credibilidade inicial do grupo para receber crédito bancário. Esses produtores, assim como no nosso estudo também utilizam comedouros fixos no manejo alimentar, mas além da ração, ofertam alimento 
natural como o microcrustáceo Artemia (recolhido nos ambientes próximos aos viveiros).

Semelhantemente aos produtores de camarão do litoral Sul do Rio Grande do Norte, os produtores da comunidade Requenguela descartam os efluentes sem tratamento prévio nos rios das proximidades (REIS, 2008), caracterizando a não utilização de bacia de sedimentação.

Segundo a Lei Cortez Pereira, no Capítulo IV, Sessão II, a produção de espécies exóticas de camarão em tanques escavados deve obedecer aos seguintes requisitos:

\begin{abstract}
haver solidez necessária à contenção de água, que garanta a sua estabilidade, comprovada por cálculos de engenharia com recolhimento de Anotação de Responsabilidade Técnica (ART); proteção dos taludes e gabiões contra a erosão; dispositivos de proteção contra a fuga de camarões para o meio ambiente tais como telas, filtros, redes, tanques de peixes nativos predadores; derivação das águas de drenagem para bacias de sedimentação, ou diretamente para rios ou estuários se apresentarem qualidade igual ou superior recebidas no ato de captação (RIO GRANDE DO NORTE, 2015, p.6).
\end{abstract}

No censo realizado em 2011 pela ABCC em convênio com o Ministério da Pesca e Aquicultura, 24\% dos microprodutores de camarão do estado do Rio Grande do Norte fazem uso de probióticos no solo, na água ou na ração, percentual este superior ao encontrado no nosso trabalho para a região estudada. Apenas $1 \%$ de todos os microprodutores norte-rio-grandenses faz uso de berçários, mas a realização de análises presuntivas é rotina para 52\% dos entrevistados (ABCC/MPA, 2011). Segundo o mesmo documento, dos $72 \%$ dos microprodutores entrevistados que possuem licença ambiental, apenas 3\% tiveram acesso a financiamento bancário para a atividade de carcinicultura (ABCC/MPA, 2011), percentual bem inferior ao encontrado na nossa pesquisa.

A baixa taxa de assistência técnica recebida pelos microprodutores da região escolhida demonstra o quanto os órgãos governamentais e ambientais estão omissos à atividade de carcinicultura e o quanto a luta desses produtores é árdua, pois encontramse sozinhos, sem apoio algum. Isso pode estar repercutindo no tipo de atividade praticada na região, pois trata-se de uma carcinicultura rudimentar e artesanal, uma vez que nenhuma fazenda possui medidas de biossegurança.

Sobre o tempo médio de um ciclo de cultivo, no estudo realizado por Figueirêdo 
et al. (2004) para fazendas de camarão em águas interiores, na região do Baixo Jaguaribe - Ceará, é entre 90 e 150 dias; esse mesmo intervalo de dias também era observado no período citado nas micro propriedades produtoras de camarão estudadas em nossa pesquisa. Das fazendas investigadas por Figueirêdo et al. (2004), 10 (cerca de $30 \%$ ) praticam a agricultura de sequeiro e irrigada na região enquanto apenas alguns entrevistados $(7,4 \%)$ no nosso estudo também trabalham com a agricultura.

No nosso estudo, todos os produtores são moradores da região e a maioria proprietários das áreas de cultivo. Reis (2008) afirma que

[...] a sustentabilidade da carcinicultura está vinculada a três variáveis básicas: ambiental, financeira e social. O princípio básico para este resultado é que o empreendimento pertença à comunidade local, pois esta tem interesse na continuidade, visando à sua prosperidade na forma de empregos para os próprios componentes familiares. Este vínculo da comunidade com sua terra propicia maiores cuidados em relação ao uso racional dos recursos naturais e às melhorias sócio-econômicas, tornando a carcinicultura sustentável; ao contrário, proprietários de empreendimentos dissociados da localidade, buscando por um retorno financeiro mais imediato, acabam pondo em segundo plano os aspectos sociais e ambientais (REIS, 2008, p.260).

Sampaio et al., (2008) investigaram os impactos socioeconômicos do cultivo do camarão marinho em alguns municípios selecionados do Nordeste brasileiro e no momento em que perguntaram aos entrevistados sobre o principal efeito da carcinicultura no município, em unanimidade responderam: aumento no emprego. $\mathrm{O}$ mesmo pode ser observado no nosso estudo quando perguntamos de que forma sua fazenda beneficia a comunidade do entorno e todos os entrevistados responderam: geração de emprego e renda.

A carcinicultura poderá mudar radicalmente o quadro socioeconômico rural de muitas regiões brasileiras, mas somente quando for efetivamente incentivada, apoiada e financiada. Essa atividade pode ainda se transformar numa alternativa à substituição do seguro defeso dos pescadores (ABCC, 2015). Alguns produtores entrevistados em nossa pesquisa antes eram apenas pescadores e viram na carcinicultura uma oportunidade de obter melhores condições de vida, pois a pesca extrativista não conseguia mais suprir as suas necessidades. Dessa forma, corroborando com Reis (2008), podemos inferir que a carcinicultura pode ser uma alternativa à própria atividade pesqueira, em função da diminuição dos estoques pesqueiros naturais. 
Segundo Vilches et al. (2008), a pobreza extrema, agravada pelo processo de degradação ambiental, contribui para a sobre-exploração dos ecossistemas. A pobreza, por exemplo, gera o desmatamento pelo uso da madeira para cozinhar, aquecer, construir casas e produtos artesanais, porque os grupos vulneráveis foram inicialmente privados de bens fundamentais, tendo acelerado a degradação do meio ambiente.

Os microprodutores de camarão entrevistados necessitam de incentivos dos órgãos governamentais para que haja a realização de uma atividade ambientalmente responsável e que possa suprir suas necessidades, havendo uma diminuição da degradação de áreas de manguezal, seja pelo aumento ilegal das áreas de cultivo ou pelo despejo de efluentes sem tratamento. De acordo com Vilches et al. (2008) o bem-estar de cada um de nós também depende, em grande parte, de que exista um nível mínimo de possibilidade de vida para todos.

\section{CONCLUSÕES}

Os microprodutores de camarão do litoral Sul do Rio Grande do Norte têm vivenciado altas taxas de mortalidade nos cultivos devido às doenças que surgiram nos últimos anos. Esse fato tem prejudicado o desenvolvimento da atividade na região, na qual tem se observado ciclos de cultivo cada vez mais curtos e com baixa lucratividade e, em muitas vezes, até com prejuízos aos produtores. Esses, em sua maioria, não dispõem de recursos para a adoção de medidas de biossegurança e o uso de novas tecnologias de produção, as quais são essenciais para o controle de enfermidades e sucesso da produção. Embora no passado tal atividade tenha gerado muito lucro para os produtores, observou-se que poucos possuem mais de um viveiro e quase todos têm a carcinicultura como uma complementação da renda familiar. As micro propriedades produtoras de camarão, representativas da região do litoral Sul do Rio Grande do Norte, têm necessitado do efetivo olhar e apoio do governo e da devida assistência técnica para que possam se adequar à carcinicultura responsável e terem boas práticas de manejo, as quais são tão almejadas pela sustentabilidade e recomendadas pela Associação Brasileira de Criadores de Camarões. 


\section{REFERÊNCIAS}

ASSOCIAÇÃO BRASILEIRA DE CRIADORES DE CAMARÃO. 2015. Cultivo do camarão marinho: Realidades Mundial e Brasileira, Mitos e Verdades sobre sua Sustentabilidade Ambiental e Contribuição para a Socioeconomia das Regiões de sua Intervenção. Disponível em: http://abccam.com.br/site/wpcontent/uploads/2015/08/Revista-ABCC-Edi\%C3\%A7\%C3\%A3o-Especial-Agosto-de2015.pdf. Acesso em 15/novembro/2015.

ASSOCIAÇÃO BRASILEIRA DE CRIADORES DE CAMARÃO. Procedimentos de Boas Práticas de Manejo e Medidas de Biossegurança para a Carcinicultura Brasileira. Natal, 2012. 49 p.

BRASIL. RESOLUÇÃO $\mathrm{n}^{\circ}$ 312, de 10 de outubro de 2002. Dispõe sobre o licenciamento ambiental dos empreendimentos de carcinicultura na zona costeira. Diário Oficial da União, Brasília, DF, 10 de out. 2002, Seção 1, p. 60.

CAVALCANTI, L. E. Aspectos geoambientais da carcinicultura no Rio Grande do Norte e seus desdobramentos legais: a implementação da licença ambiental em defesa do meio ambiente. Revista dos Estudantes de Direito da UnB, n. 10, p. 71-88, 2012.

CAVALLI, R. O. e FERREIRA, J. F. O futuro da pesca e da aquicultura marinha no Brasil: a maricultura. Ciência e Cultura, São Paulo, v.62, n.3, 2010.

CONVÊNIO ABCC/MPA. 2011. Levantamento da infraestrutura produtiva e dos aspectos tecnológicos, econômicos, sociais e ambientais da carcinicultura marinha no brasil em 2011. Disponível em: http://www.mpa.gov.br/files/docs/Informacoes_e_Estatisticas/Livro\%20ABCC.pdf Acesso em 10 dezembro 2015.

COSTA, E. F. e SAMPAIO, Y. Geração de Empregos Diretos e Indiretos na Cadeia Produtiva do Camarão Marinho Cultivado. Revista Economia Aplicada, v.8, n.2, p.119, 2004.

FAO. Food and Agriculture Organization of the United Nations. The state of world fisheries and aquaculture. Rome, 2008.

FIGUEIRÊDO, M. C. B.; ROSA, M. F.; ARAÚJO, L. F. P.; CORREIA, L. J. A.; MORAIS, L. F. S. Perfil das Fazendas de Camarão em Águas Interiores, na Região do Baixo Jaguaribe. Revista Brasileira de Recursos Hídricos, v.9, n.3, p.101-108, 2004.

LOPES, F. D. e BALDI, M. Estratégia como contexto interfirma - uma análise a partir da imersão social e da teoria institucional no setor de carcinicultura norte-rio-grandense. Revista de Administração Mackenzie, v.14, n.2, p. 210-242, 2013.

REIS, J. N. P. Sustentabilidade na Produção de Camarão: O Caso da Comunidade de Requenguela, no Município de Icapuí - Ceará. Revista Econômica do Nordeste, v.39, 
n.2, p.251-262, 2008.

RIBEIRO, L. F.; SOUZA, M. M.; BARROS, F.; HATJE, V. Desafios da carcinicultura: aspectos legais, impactos ambientais e alternativas mitigadoras. Revista de Gestão Costeira Integrada, v.14, n.3, p.365-383, 2014.

RIO GRANDE DO NORTE (Estado). Lei No 9.978, de 09 de setembro de 2015. Dispõe sobre desenvolvimento Sustentável da Carcinicultura no Estado do Rio Grande do Norte e dá outras providências. Diário Oficial do Estado, Poder Legislativo, Rio Grande do Norte, Natal, 09 set. 2015.

SAMPAIO, Y.; COSTA, E. F.; ALBUQUERQUE, E.; SAMPAIO, B. R. Impactos socioeconômicos do cultivo de camarão marinho em municípios selecionados do Nordeste brasileiro. Revista Brasileira de Recursos Hídricos, v.46, n.4, p.1015-1042, 2008.

SANTOS, C. H. A.; LOURENCO, J. A.; BAPTISTA, R. B.; IGARASHI, M. A. Crescimento e sobrevivência do camarão branco do pacifíco Litopenaeus vannamei (Boone, 1931) em diferentes salinidades. Ciência Animal Brasileira, v.10, n.3, p. 783789, 2009.

SCORVO FILHO, J. D.; FRASCÁ-SCORVO, C. M. D.; ALVES, J. M. C.; SOUZA, F. R. A. A tilapicultura e seus insumos, relações econômicas. Revista Brasileira de Zootecnia, n.39, p.112-118, 2010. 